\title{
Designing Educational Web pages for Post Operative Nursing Care
}

\section{Isra Natheer Alkallak}

Dep. of Medical Basic sciences

College of Nursing

University of Mosul

\section{Sana Thanoon Ahmad}

Dep. of Medical Clinical sciences

College of Nursing

University of Mosul

\section{Omar Akram Alsafar}

College of Nursing

University of Mosul

\author{
Accepted \\ 03 / 10 / 2007
}

\section{الخلص ةa}

تناول البمث إلى رط تكنولوجيا المعلوملت مع مهنة التمريض م ن خ خلما إذ ششاء

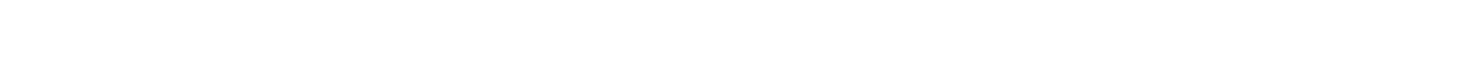

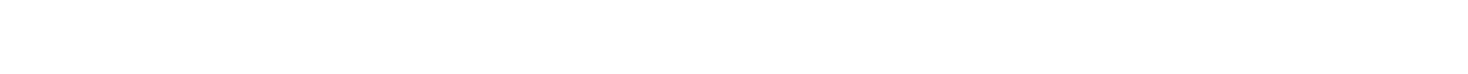

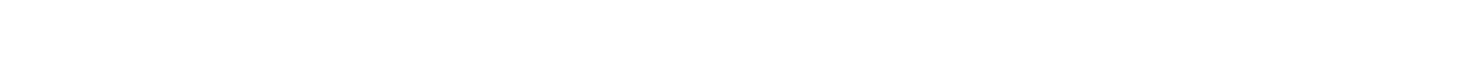

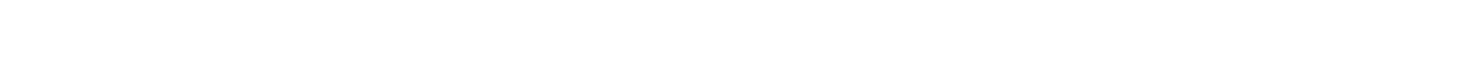
معلوماتها بدلاً من الجهد المبذول في مطالعة الكتب والمصادر.

\begin{abstract}
This research drives at connecting information technology to nursing. This is to be carried out by way of designing an educational site for medical and nursing care to be performed post operative care to patient on the internet.

The site's function is to expose various related windows (pages) relevant to nursing care in post operative. The information to be projected include data, texts, figures pics and animations which facilitate navigation for the visitor and provide information which may save a lot of effort and time devoted to book and reference searching.
\end{abstract}




\section{1-1 Introduction}

The post operative care phase begins with the admission of the patient to the recovery area and ends with follow-up evaluation in the clinical setting or at home .The scope of nursing covers a wide-range of activities during this period .Smeltzer \& Bara(7).

In the immediate post operative care the client post operative condition should be assessed, the nurse relies on information from nursing assessment and on knowledge regarding the surgical procedure performed and events occurring during surgery .

The nurse must be able to detect change a variation from the information of the harm may be indicates on set of surgically related complication . Potter\& Perry(5).

The internet are essentially lines of communications enveloping the terrestial globe from all directions. They are employed to exchange information of all types and sorts digital, visual or audio-visual storing them and retrieving them at click on the mouse.

The net, therefore, is a global communication system through which millions of people communicate by computers .

The internet is so far the most important innovation in the world of information technology. It is used to send and receive E-mails, shopping and news reading, besides games and entertainment. الز غبي وآخرون(9) .

Accordingly, the internet is a data-base people possess and every subscriber enters his/ her own personal details whether he or she be a tradesman offering his product, a scholar publicizing his papers or a company seeking recruits. It stream lines scattered and dispersed pieces of information from all over the world and pour them in a single outlet.

\section{Objectives of The Research}

The research tackles the tasks involved in a site design for post operative nursing care on the internet for the benefit of the student or the reader visiting the site with ease, precision and speed instead of book mongering over references and titles .

\section{1-2 Requirements and structure}

\section{The Requirements for site design}

To design pages on the internet, it is necessary to perform the following :

1- Objective Setting:- Objective must be set in advance of page writing and page organization. There are a lot of objectives, some are educational as is the case with our research, others are commercial, recreational, or political. 
2- Information or Data Collecting:- Prior to design, a designer must have all the needful information and materials to be shown on pages, ready for production and arrangement on two-dimensional space.

3- The Production of First or Home Page:- Success does largely depend on the quality of the first page, its organization, and distribution of materials in it. Thus, this page must contain the name of the site and links to other related pages and /or subjects.

4- Design of Pages:- It is plausible to employ one of the computer languages in organizing, and editing various pages, among these languages are HTML and Front Page, etc.

5- Test:- The site designer must test his / her site as it he / she were visiting it for the first time, this to make sure that links and references are correct and precise before any visitor may call and find about defects.

6- Reconstruction and Addition:- Setting a site and leaving it as it is for a long time will cause monotony and boredom. It turns into a relic or a deserted house that needs to be reinnovated, revitalized and redecorated in order to, once again, calls the visitors interest.

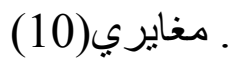

\section{1-3 Structure}

Technologies such as extensible hyper text markup language (HTML), java script, Dream weaver are used to build the portion of webbased applications that reside on the client side. (i.e., the portion of applications that typically run on web browsers such as Microsoft's internet explorer). The world wide web allows computer users to locate and view multimedia- based documents (i.e., documents with text, graphics, animations, audios or videos) on almost any subject. Java allows programmers to create web pages that contain dynamic \& interactive content. Developers can also use java to create large-scale enterprise applications, to enhance the functionality of web servers, to provide applications for consumer device and much more. The java script language facilitates a disciplined approach to the design of computer programs that enhance web pages. Dream weaver is a useful tool for creating and maintaining web pages. Dream weaver allow users to apply text formatting and insert image, lists, tables, and forms into web pages with relative ease. The graphics editing skills learned through photo shop. Elements can be applied to other graphics editors, such as Adobe photo 
shop. photo shop elements performs screen captures and adds the convenience of being able to edit them. The two major file formats used for images are GIF and JPEG. GIF is best for screen captures, line drawings and other graphics with sharp edges. JPEG is ideal for images with "color complexity" such as photographs and original art .

A personal home page can be specified, the home page is the web page that load when the browser is first opened and appears when the home button at the top of the browser window is clicked. The most successful web pages use both text and graphics to enhance the user experience. Deitel et al(1), www from internet(8). Home page contains some buttons for the site they are:-

- Introduction .

- Aims .

- Care includes .

- Complication .

- References .

- About the site .

When pushing this button, we have the main page, the page which is referred to whenever the viewer wants to go back to it with a simple introduction. Care including part when pushing this button we have containing the following buttons:-

1. Protect the patient from injury .

2. Maintain respiratory function .

3. Prevent circulatory stasis .

4. Position .

5. Ambulation .

6. Bed exercises .

7. Check the vital signs .

8. Maintain normal nutrition status .

9. Promote bowel elimination .

10. Promote urinary elimination .

11. Promote wound healing .

12. Maintain rest and comfort .

13. Prevent infection .

14. Maintain psychological health .

15. Maintain adequate fluid volume . See figure (1). 


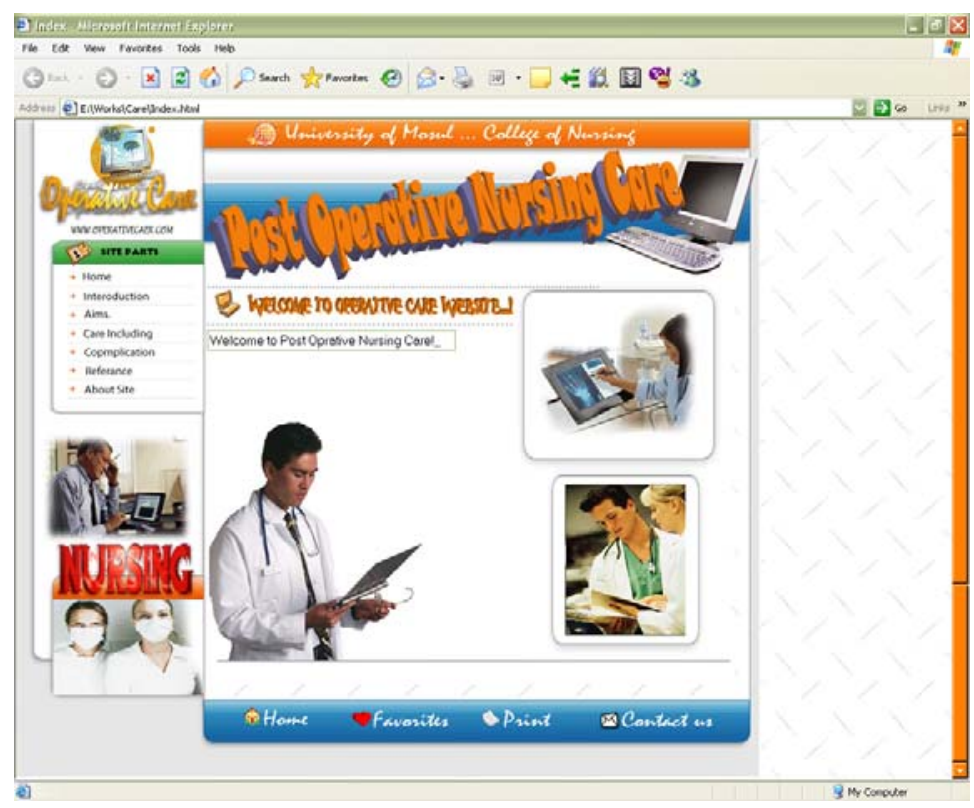

Figure (1)

\section{1-4 Host Web Site}

When finishing creating a website, a host site is needed attached to internet device. Use the server to login to our web site and review it. The place where to put this site is called web space and there are a great number of hosting companies providing free web space but under certain conditions .

\section{Methodology}

\section{2-1 Protect The Patient From Injury}

1- Maintain an open airway is a priority measure:- The client position must be on the side or with the head turned to the side to prevent aspiration. If not contraindication.

2- Side rails:- Are kept raised for safety until patients are full recovered from anesthesia.

3- The surgical site:- Is checked when the patient returns to the unit the surgical site should be checked each 1 hour for first 4 hours, then every 2 hours if bleeding has not been occurring.

4- Sense of position:- Will return to the legs first, and then sensation to deep pressure, voluntary movement. And then feeling of super facial pain and temperature .

5- The dressing:- Should be dry and not changed without an order to do so . Dewit(2). See figure (2) 


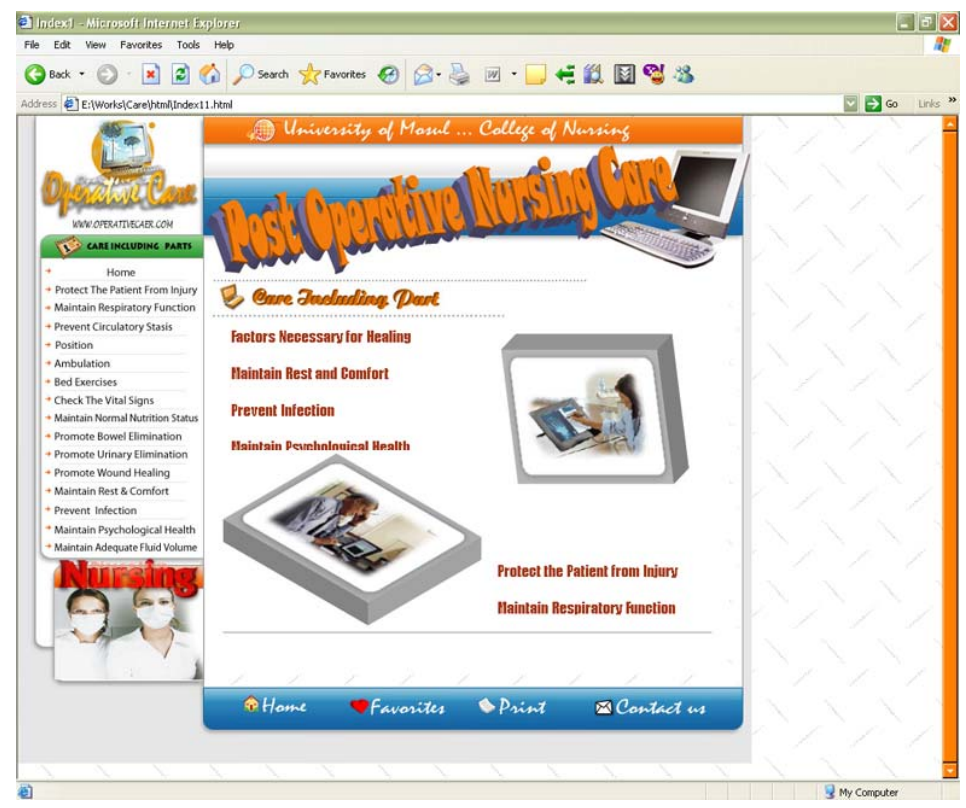

Figure (2)

\section{2-2 Maintain Respiratory Function}

To prevent respiratory complication the nurse begins aggressive pulmonary hygiene measures early. Potter \& Perry(6). And maintain airway, if client remains sleepy or lethargic must keep head extend and support in side lying position. Smeltzer \& Bara (7).

The following measures promote expansion of the lungs:

1- The nurse encourages diaphragmatic breathing exercises.

2- The nurse instruct client to use incentive Spiro meter for maximum inspiration.

3- The nurse encourage turning, coughing, deep breathing and pulse ambulation will assist in prevent pneumonia .

4- Keep the client comfortable. Potter \& Perry (6) .

5- Auscultation the lungs carefully for absence of sound or crackles indicating retained secretion, assess the rate and deep breathing. Dewit (2). See figure (3). 


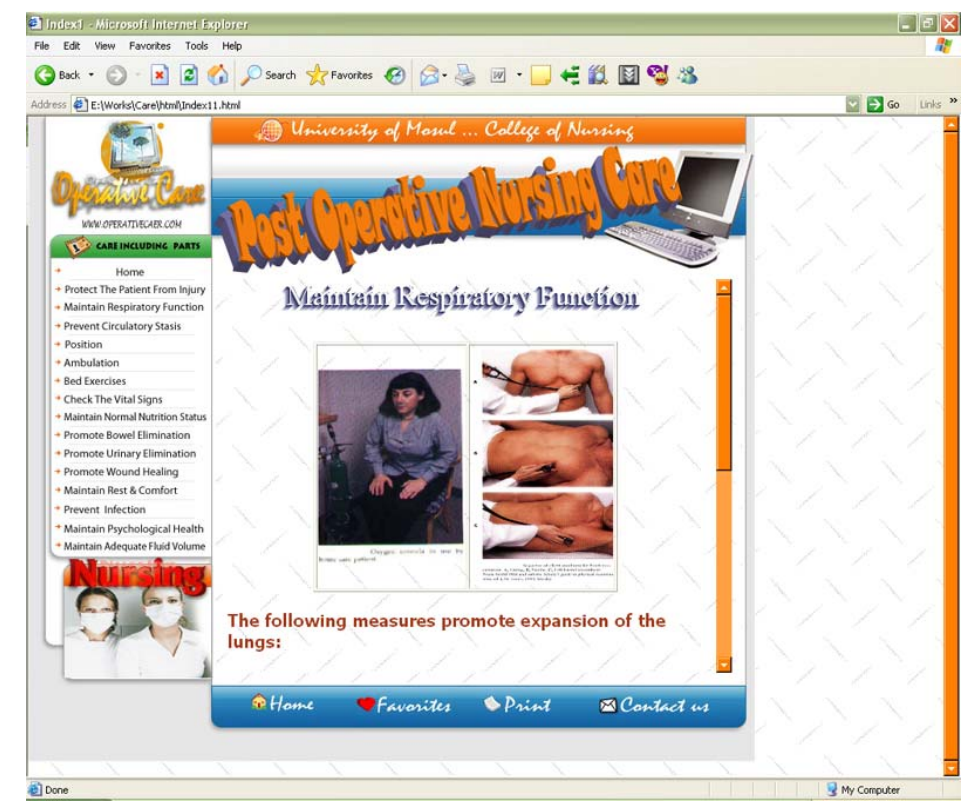

Figure (3)

\section{2-3 Prevent Circulatory Stasis}

Early measure directed at preventing circulatory stasis the nurse routinely assesses for humans sign in post operative period.

The following measures promote normal venous return and circulatory blood flow :

1- The nurse encourages clients to perform leg exercises at least every hours while awake.

2- The nurse encourages early ambulation most clients are expected to ambulate the every surgery.

3- Depend on the severity of surgery and their condition.

4- The nurse avoid positioning clients in a manner that interrupts blood flow to extremities.

5- Prevent concentrated build up of formed blood elements by adequate fluid intake orally or intravenous. Potter \& Perry (6). See figure (4). 


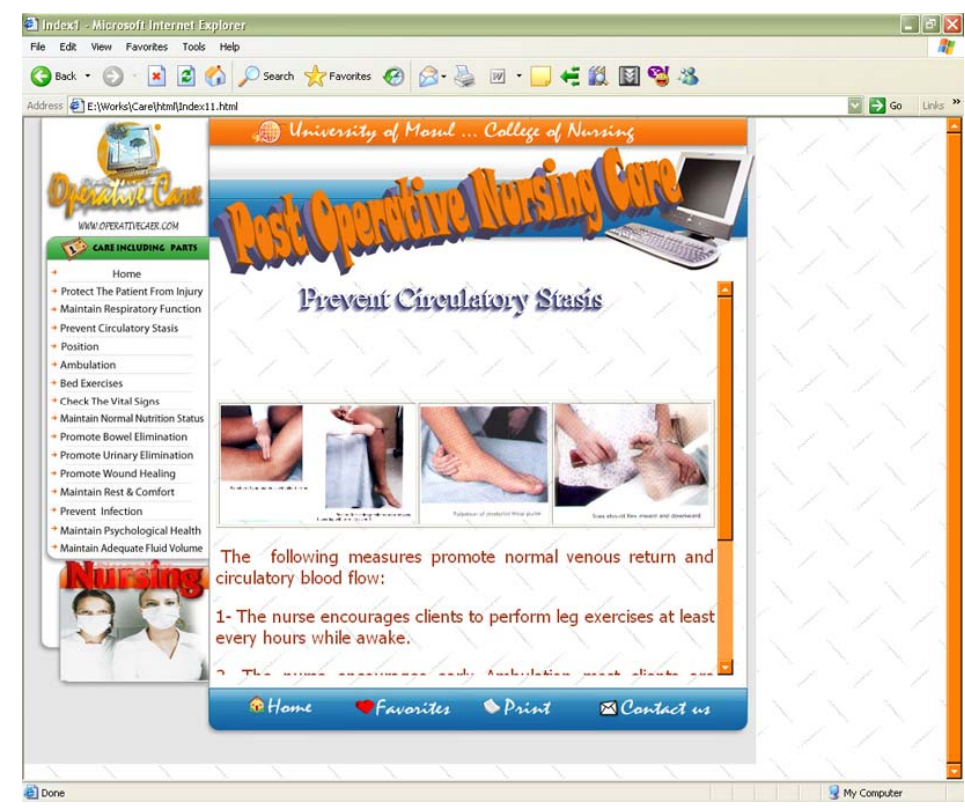

Figure (4)

\section{2-4 Position}

The patient with limited mobility must be turned from side to side least every 1 hours, the patient position must be changed when discomfort. Smeltzer \& Bara (7) and must turning the clients head to the side to prevent vomiting. Ignatavicius et al (4). The following types of position:

1- Lateral position:- This position use when the patient is desirable to change position frequently, to aid in the drainage of cavities, such as chest and abdomen. And prevent post operative respiratory and circulation complication.

2- Supine position:- This position use of the patient's placed immediately after surgery, bed covers should not restrict the movement of the patient's twos and feet.

3- Fowler's position:- The patient trunk is raised to an angel of 60 to 70 degree, this is comfortable position. Smeltzer \& Bara (7).

\section{2-5 Ambulation}

Surgical patient are encourage to be out of bed as soon as indication, this is determined by the stability of a patient's cardiovascular and neuromuscuture of the surgery performed.

The advantage of early ambulation is that it reduces the indication of post operative complication. The condition of the patient must be the deciding factors and a progression of steps the following in mobility the patient: 
1- Nursing support and encouragement with safety as the main concern. The patient is helped to move gradually from the lying position to sitting position. Until any evidence of dizziness has passed.

2- The patient may then be placed completely up right and turned so that both legs hang over the edge of the bed.

3- After this preparation the patient may be helped to stand be side the bed. Smeltzer \& Bara (7). See figure (5)

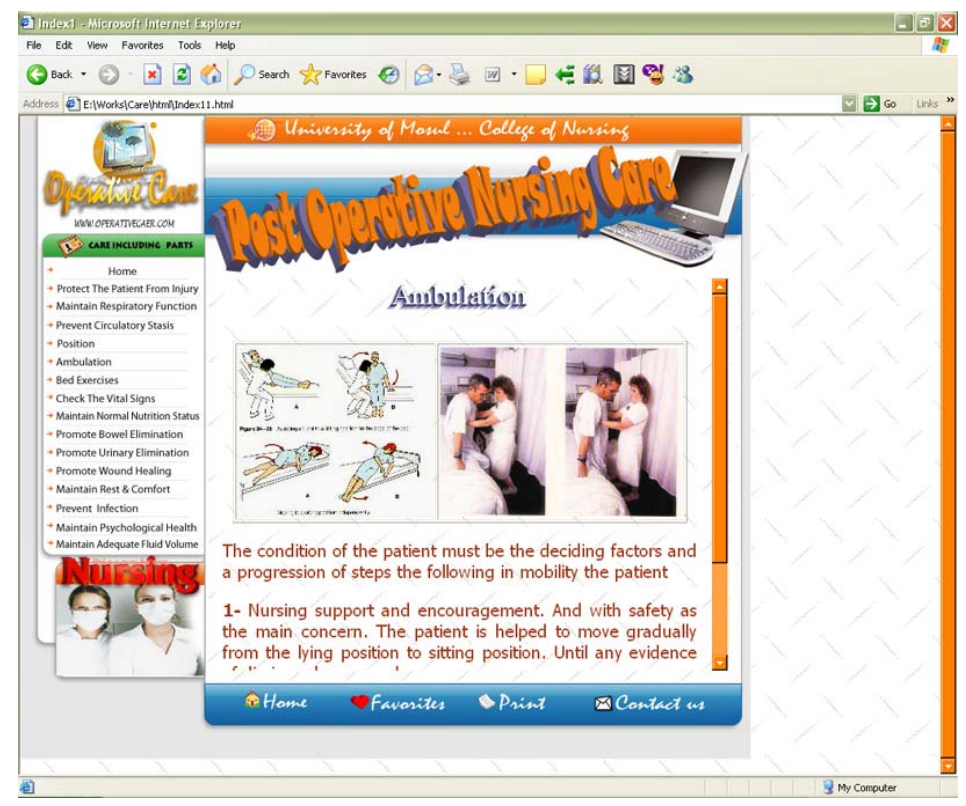

Figure (5)

\section{2-5 Bed Exercises}

When early ambulation is not feasible. General exercises may achieve some degree of desirable result. General exercises should begin as soon after surgery as possible preferable with in the first 24 hours and are performed under super vision, to ensure that they are done properly and in safe manner. The purpose of bed exercise is promoting circulation and prevents the development contractures as well as to permit the patient the fullest return of physiologic functions.

Types of exercises include the following:

1- Deep-breathing exercises for complete lung expansion.

2- Arm exercises through the full range of motion with specific attention to abduction and external rotations of the shoulder.

3- Leg flexion and leg lifting exercises to prepare the patient for ambulation activities.

4- Abdominal and gluteal contraction exercises. Smeltzer \& Bara(7). See figure (6) 


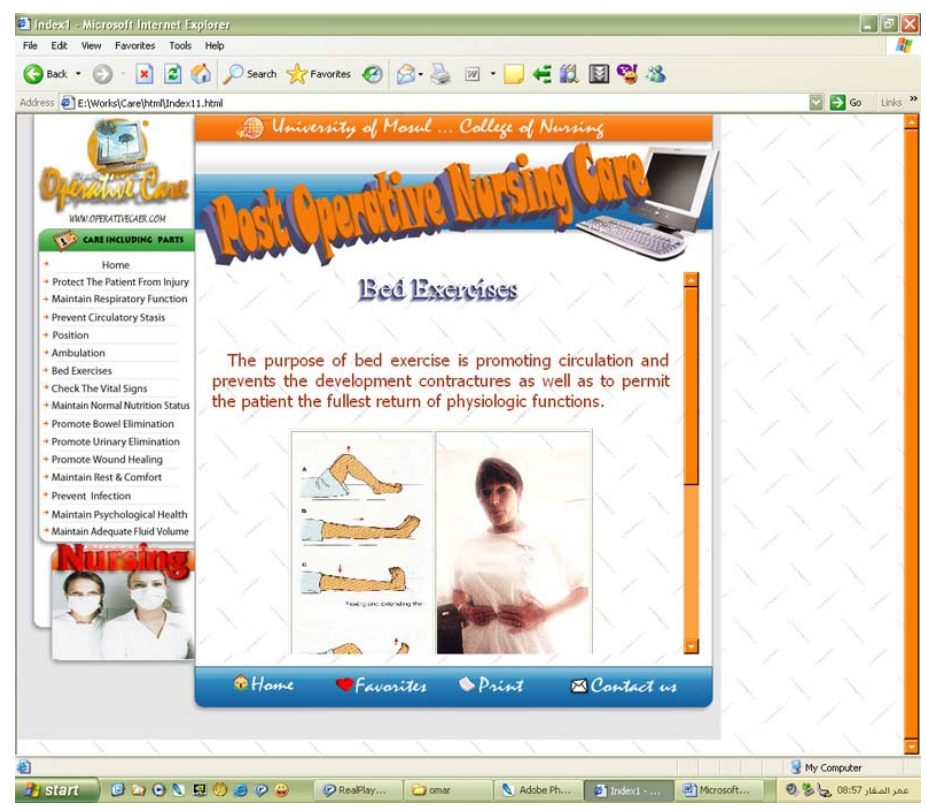

Figure (6)

2-6 Check the vital signs

Assess vital signs at least every 24 hours or as ordered the temperature above $38 \mathrm{c}^{\circ}$ in first 48 hours may indicate otelectasis, the normal inflammation response or dehydration, elevation above $37.7 \mathrm{c}^{\circ}$ on the third day or after may indicate wound infection, pneumonia, or phlebitis. Elkin et al (3).

A decrease in the client blood pressure, pulse and heart sound indicate possible myocardial depression, fluid volume deficit, shock hemorrhage. The pulse rate can increase in indication of hemorrhage and pain. Vital signs are often recorded every 15 minutes for 4 times, every 30 minute for 4 times, every 2 hours for 4 times, then every 4 hours for 24 to 48 hours if the client condition is stable. The vital signs are assessed according to the facility's policy, the client condition and the nurse judgment. Potter \& Perry (6).

The normal range of vital signs

Temperature (36.7-37.2 $\mathrm{c}^{\circ}$ ).

Pulse [50-100] beats / $\mathrm{min}$.

Respiration [14-24] breaths / $\mathrm{min}$.

Blood pressure [80-120] Hg/mm . see figure (7) 


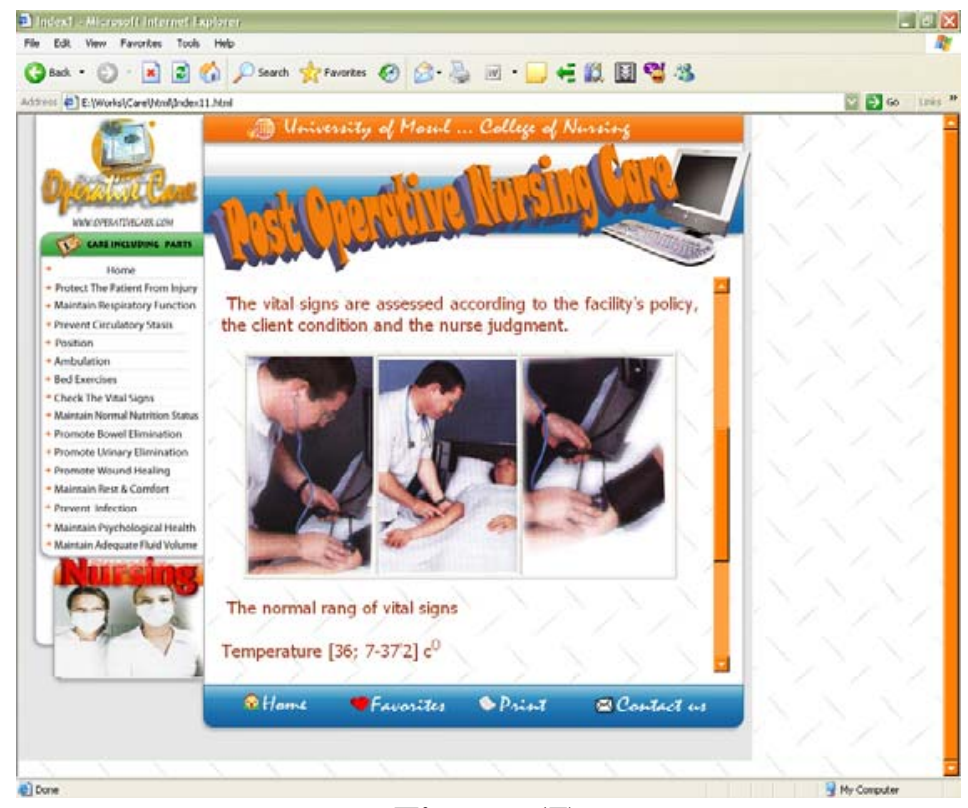

Figure (7)

\section{2-8 Maintain normal nutrition status}

When heard the bowel sound give liquid are usually first substances desired and tolerated by the patient after surgery (water, fruit juices and tea) may be given in large amount if vomiting dose not occurred .

Soft food (gelatin, junket, custard and milk), that supply additional calories and nutrient are added gradually after clear fluids have been tolerated. as soon as the patient tolerated soft foods well, solid food may be given. Smeltzer \& Bara(7).

The following measure maintains an adequate dietary intake :-

1- The nurse removes sources of noxious odors .

2- The nurse assist the client to a comfortable position during meal time, the client should site for minimize pressure on the abdomen .

3 - The nurse provides frequent oral hygiene. Adequate hydration and cleansing of oral cavity eliminate dryness and bad tastes. Dewit(2). See figure (8). 


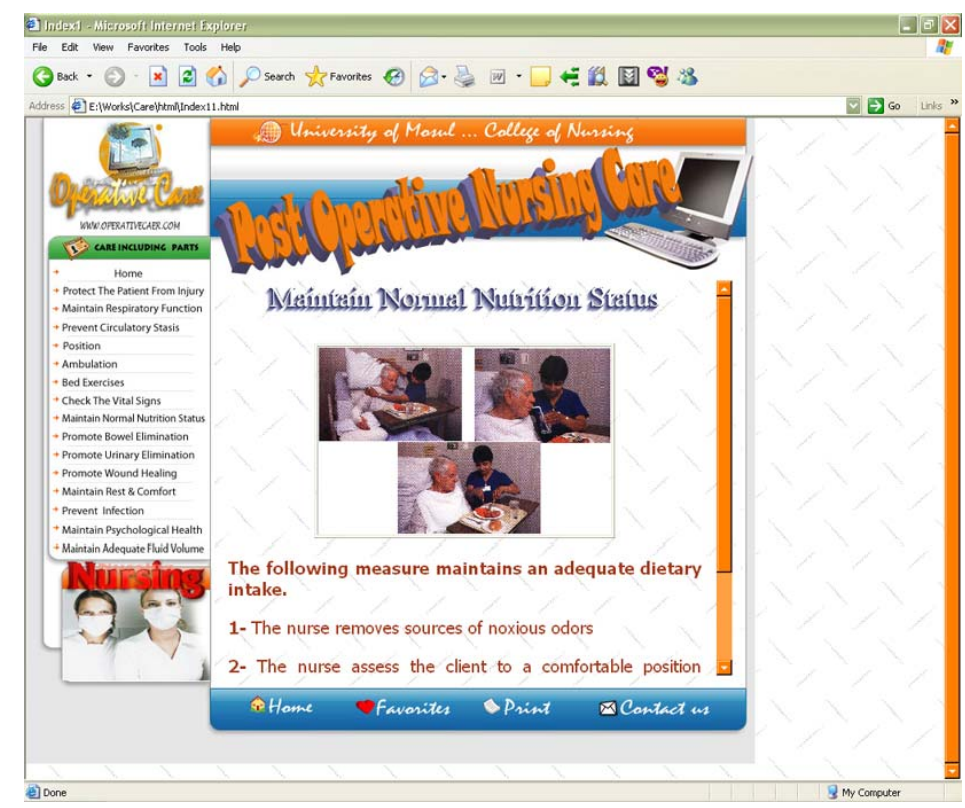

Figure (8)

\section{2-9 Promote Bowel Elimination}

Preoperative bowel preparation, immobility, possible intestinal manipulation during surgery and reduce oral intake can all affect on bowel function. Smeltzer \& Bara(7).

The following measures promote return of normal elimination :-

1- The nurse routinely auscultation the abdomen to detect return of normal bowel sounds 5 to 30 loud gurgles per minute.

2- The nurse asks if the clients is passing gas (flatus), this important signs indicating normal bowel function.

3- The nurse promote ambulation and exercises.

4- The nurse maintains an adequate fluid intake, fluids keep fecal material soft for easy passage.

5- The nurse administers enemas, rectal suppositories and rectal tube as ordered. Dewit (2).

\section{2-10 Promote Urinary Elimination}

The depressant effects of anesthetics and analgesics impair the sensation of bladder fullness, the client should void within 8 to 12 hours after surgery. Clients who under go surgery of the urinary system frequently have Foley catheters inserted to maintain free urinary flow until voluntary control of urinary returns. 
The following measures promote urinary elimination :-

1- The nurse assist the client to assume normal position during voiding.

2- The nurse assess for bladder distention, if the client dose not void within 8 hours of surgery, it may be necessary to insert urinary catheter.

3- The nurse monitors the fluid intake and out put by report. Dewit(2). See figure (9).

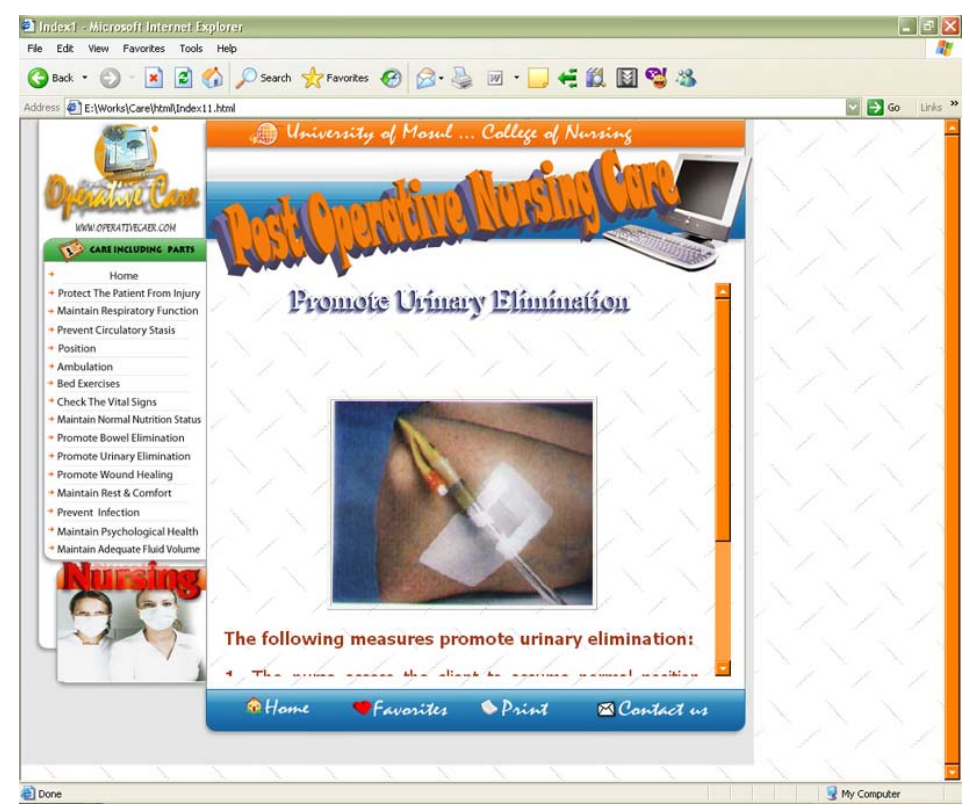

Figure (9)

\section{2-11 Promote wound healing}

1- The nurse documents the reinforcement, as well as the color, type, amount and odor of drainage fluid and the time of observation, in the client's chart.

2- The nurse assess the surgical area frequently and reports any unexpected findings to the surgeon.

3- Wound care usually include changing and care of dressing, assessment of the wound for signs of infection, and care of drains including emptying, measuring and documenting characteristics. Potter \& Perry (6).

4- The nurse use aseptic techniques during dressing change and wound care.

Dewit (2). See figure (10). 


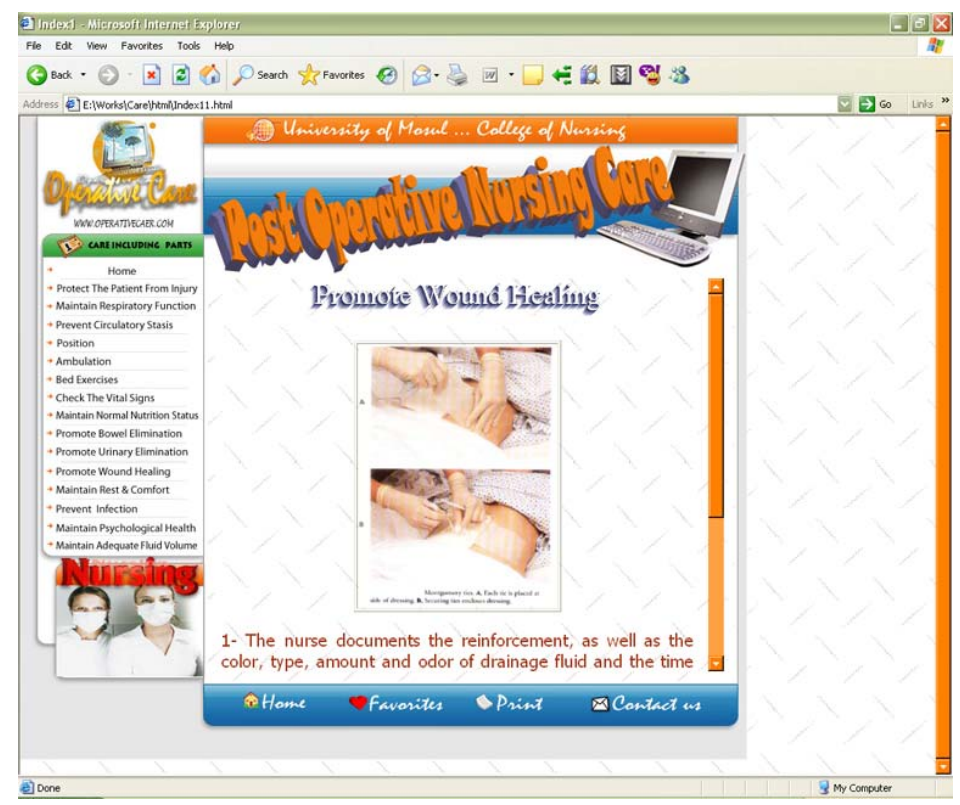

Figure (10)

\section{2-12 Factors necessary for healing}

\section{A- Local :}

1- $\quad$ Adequate haemostatic (for clot formation).

2- $\quad$ Rest for area (assure formation of clot).

3- $\quad$ Apposition of skin edges if possible.

4- $\quad$ Adequate blood supply to ensure blood and $\mathrm{O}_{2}$.

5- $\quad$ Freedom from infection.

\section{B- General :}

1- Age ,younger patient have more action cells.

2- Nutrition: protein, vitamin A \&C, vita K.

3- Adequate circulation. Potter\& Perry(5).

\section{2-13 Maintain rest and comfort}

Postoperative restlessness may be symptom of oxygen deficit or hemorrhage, this must assess by monitor the vital signs. Smeltzer \& Bara(7). However, the most common causes the general discomfort is:-

1- Pain:- a surgical client's pain increase as anesthesia wares off, the incision area may be only one source of pain therefore the nurse should be give analgesic. Dewit (2).

2- Reduce stress on suture line, helps client relax and promote comfort. Ignatavicius et al (4). 
3- The patient may feel cold and should be keep warm.

4- Dressing on extremities should be checked to be certain that they are not so tight that circulation is cut off, Check vital signs. Elkin et al(3). See figure (11).

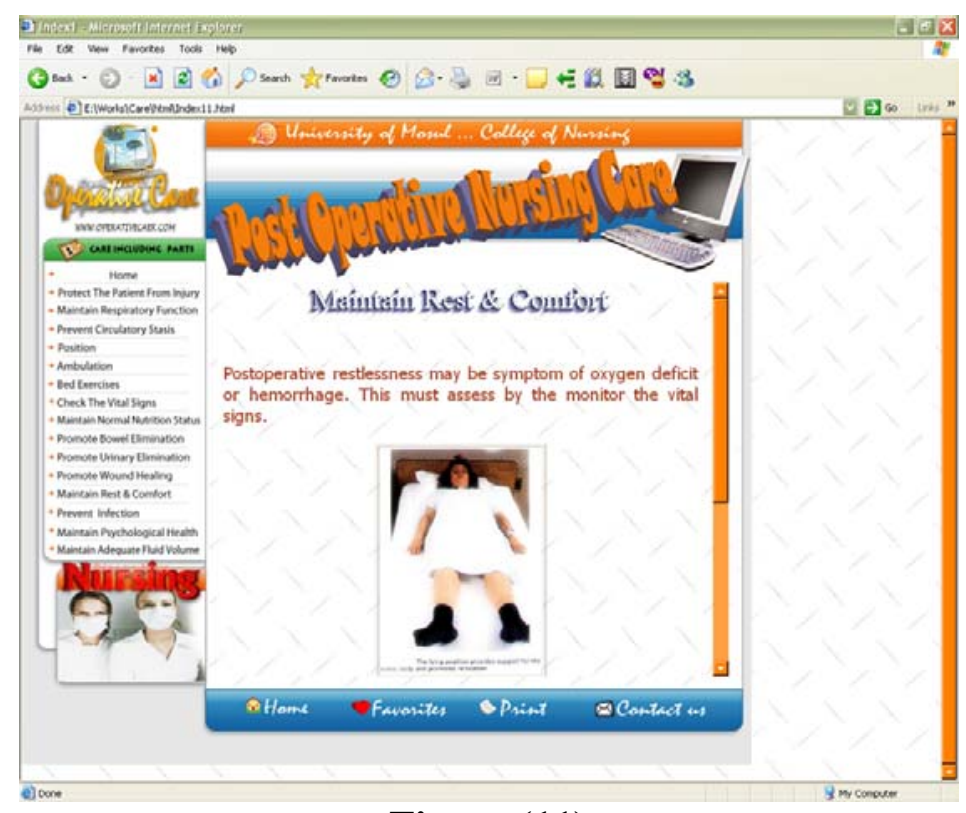

Figure (11)

\section{2-14 Prevent Infection}

Cause of infection :

1- Intact skin and mucous membranes have been invaded by tubes and catheters, by disease process or by the surgical procedure.

2- The effect of anesthesia and surgery reduce the resistance of the body to infection.

3- Exposure to infection agent.

4- Their is breaks in aseptic technique .Smeltzer \& Bara(7). See figure (12). 


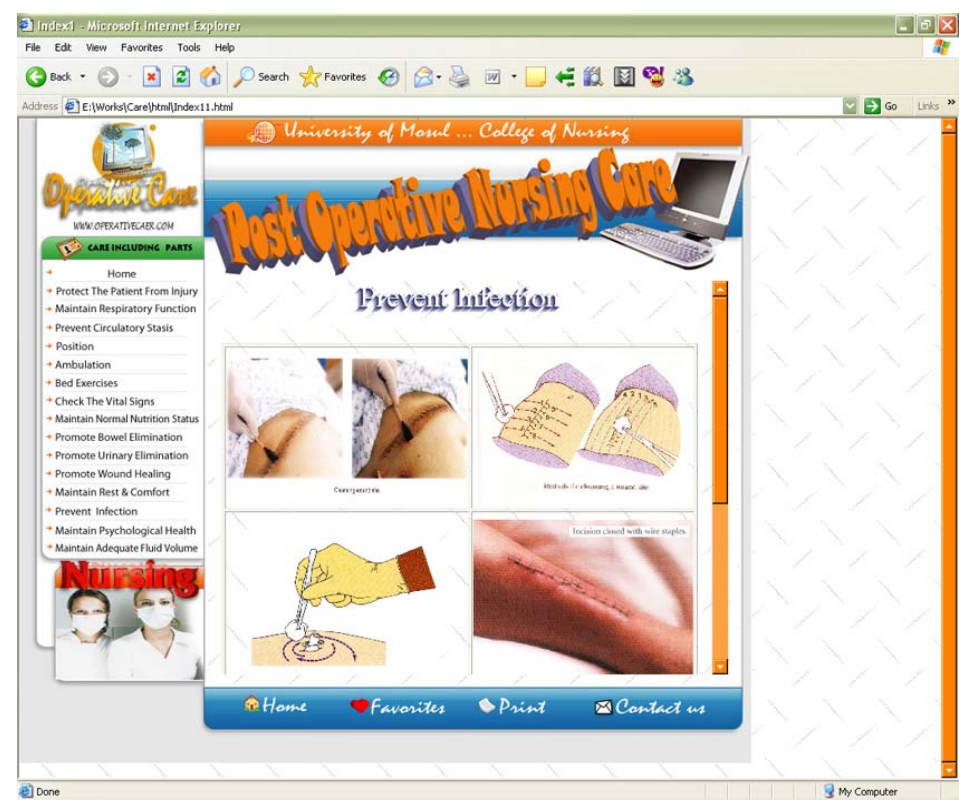

Figure (12)

\section{2-15 Nursing care infection}

1- Aseptic technique must be used when caring for the postoperative patient.

2- Good hand washing is the primary means of prevent infection.

3- Encouraging the increase fluid intake will help prevent bladder infection.

4- Dressing changes are performed with strict aseptic techniques. Elkin et al (3).

2-16 Maintain psychological health

1- As the nurse completes the physical aspect of post operative assessment the psychological, social and cultural characteristics of the client are consider.

2- Physical signs that may indicate anxiety including restlessness, increase pulse, blood pressure, and respiratory rate and crying.

3- Maintain the client's psychological health by :

a- prevent unnecessary stressors.

b- Allow the client liberal visitation of supportive.

c- Enable the client to utilize individual successful coping mechanisms.

d- Keep the client well groomed and bathed Potter \& Perry (6).

See figure (13) 


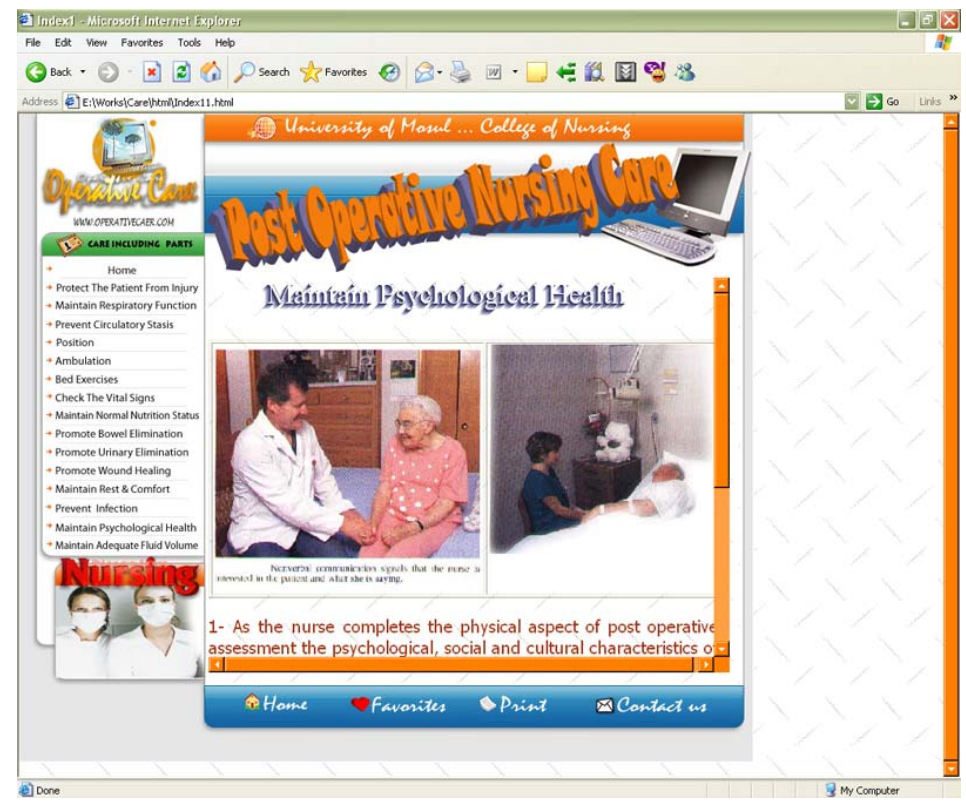

Figure (13)

\section{2-17 Maintain adequate volume}

A considerable loss of body fluids occurs with surgery because of increase perspiration, increase mucus secretion in the lungs and loss of blood to combated the loss of fluid. See figure (14).

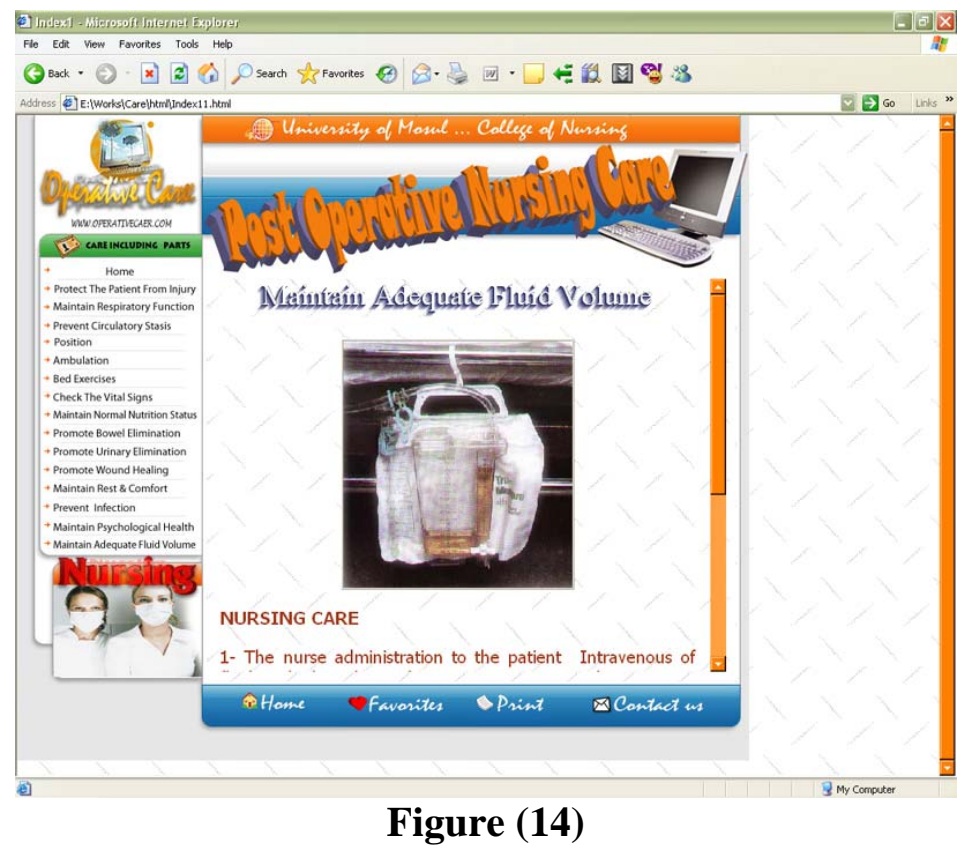




\section{2-18 Nursing care of fluid and electrolyte}

1- The nurse administration to the patient intravenous of fluid and electrolyte solution continues in to the operative period to :-

a- assure fluid and electrolyte balance.

b- electrolyte levels.

c- vital signs.

d- Urine output.

2- monitored closely and abnormalities are reported so that appropriate treatment can be initiated. The type of fluid replacement depended on the type amount lost as well as the condition of the patient Smeltzer \& $\operatorname{Bara}(7)$.

\section{2-19 Complication of the postoperative}

The danger inherent in surgery involves not only the risk of the surgical procedure but also the hazard of postoperative complication that may prolog convalescence or adversely affect the surgical outcome.

The nurse plays an important part in the prevention of these complication and collaborates with physician and other members of the health care term in their management, should they occur. Major postoperative complication includes :-

Shock, hemorrhage, deep vein thrombosis (DVT), pulmonary embolism, respiratory complication, such as hypoxemia, otelectasis, and pneumonia.

Among others: urinary retention, intestinal obstruction, and possible postoperative psychosis. Smeltzer \& Bara(7).

\section{3-1 Results}

- The aim of this website is to create pages of certain authority, linked together through hyper texts to view the information about certain subject. The subject of this page is post operative nursing care entitled in special one used by internet users to review the pages of this website.

- The use of information technology in the nursing. 


\section{3-2 Conclusions}

- Obtaining the recent information relative to the subject from varied resources.

- To enrich the scientific expertise by acknowledging the affective developed technologies.

- To use internet to develop research efficiency.

- To publish some articles and researches.

\section{3-3 Recommendation}

- Creating websites about the nursing care of the patient before and intra the surgery.

- Transform knowledge and search for information from its classical way in to an electronic form through electronically infrastructures to find common grinds of informational and communicative systems to spread electronic education among students and researchers in future.

\section{References}

1- Deitel, H. M., Deitel, P. J. and Goldberg, A. B., " Internet \& World Wide Web How to Program" $.3^{\text {rd }}$ Ed. Prentice Hall, Upper Saddle River,NJ: (2004) .

2- Dewit, S. C., " Fundamental concepts and skills". $1^{\text {st }}$ Ed. W.B., Saunders company, U.S.A. (2001), pp. (751-776).

3- Elkin, M. K. Perry, A. G. and Potter, P. A.," Nursing Intervention Clinical Skills ". $3^{\text {rd }}$ Ed. Mosby, U.S.A. (2004), pp(520-535) .

4- Ignatavicius, D. D. Workman, M. L. and Mishler, M. A. "Medical Surgical Nursing". $2^{\text {nd }}$ Ed. W.B.,Saunders company, U.S.A. (1995), $\mathrm{pp}(410-430)$.

5- Potter, P. A. and Perry, A. G.," Fundamental of Nursing concepts". $3^{\text {rd }}$ Ed . Process and Paretic, Mosby, U.S.A. (1993), pp(1635).

6- Potter, P. A. and Perry, A. G., "Fundamentals Nursing". $4^{\text {th }}$ Ed. Mosby, U.S.A. (1997), pp(1418-1428).

7- Smeltzer, S. C. and Bara, B. G.,"Medical Surgical Nursing". $8^{\text {th }}$ Ed. Lippincort, U.S.A. (1995), pp(396-423).

8- $\underline{\text { www.w } 3 \text { cschools.com }}$ 


\section{المصارر العربية}

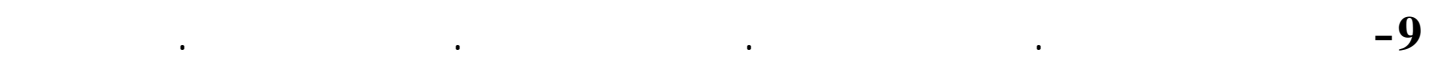

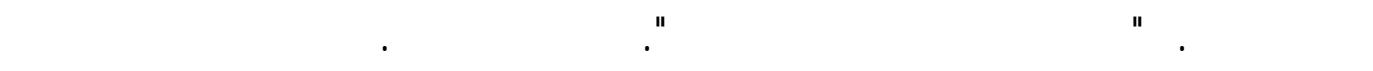

$$
\text { (2004)، ص(351) - 352) }
$$

10 - مغايري، مازن.، "تعلم الانترنيت (دورة في كتلب)". الطبعة الأوله. دار الرضوان،

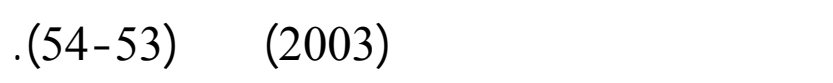

